\title{
Rehabilitation in Patients before and after Lung Transplantation
}

\section{Daniel Langer}

Faculty of Kinesiology and Rehabilitation Sciences, KU Leuven, and Respiratory Rehabilitation and Respiratory Division, University Hospital Leuven, Leuven, Belgium

\section{Key Words}

Lung transplantation - Exercise training - Limb muscle dysfunction · Exercise capacity · Quality of Life · Physical activity

\begin{abstract}
Lung transplantation is an established treatment for patients with end-stage lung disease. It has been observed that despite near-normal lung function, exercise intolerance and reductions in quality of life (QOL) often persist up to years after transplantation. Several modifiable pre- and posttransplant factors are known to contribute to these persisting impairments. Physiological changes associated with severe and chronic lung disease, limb muscle dysfunction, inactivity/deconditioning, and nutritional depletion can affect exercise capacity and physical functioning in candidates for lung transplantation. After transplantation, extended hospital and intensive care unit stay, prolonged sedentary time, persisting inactivity, immunosuppressant medications and episodes of organ rejection may all impact lung recipients' recovery. Available evidence will be reviewed and content will be proposed (both evidence and experience based) for rehabilitation interventions prior to transplantation, during hospitalization after transplantation, and in both the immediate
\end{abstract}

( $\leq 12$ months after hospital discharge) and long-term (>12 months after hospital discharge) posttransplant phase. Outpatient rehabilitation programs including supervised exercise training have been shown to be effective in improving limb muscle dysfunction, exercise capacity, and QOL both before and after transplantation if offered appropriately. Unmet research needs included the absence of sufficiently powered randomized controlled trials measuring the effects of rehabilitation interventions on crucial long-term outcomes such as sustained improvements in QOL, participation in daily activity, survival, incidence of morbidities and cost-effectiveness. Remotely monitored (telehealth) home-

Previous articles in this series: 1 . Osadnik CR, Rodrigues FMM, Camillo CA, Loeckx M, Janssens W, Dooms C, Troosters T: Principles of rehabilitation and reactivation. Respiration 2015;89:2-11. 2. Holland $A E$, Dowman $L M$, Hill CJ: Principles of rehabilitation and reactivation: interstitial lung disease, sarcoidosis and rheumatoid disease with respiratory involvement. Respiration 2015;89:89-99. 3. Burtin $\mathrm{C}$, Hebestreit $\mathrm{H}$ : Rehabilitation in patients with chronic respiratory disease other than chronic obstructive pulmonary disease: exercise and physical activity interventions in cystic fibrosis and non-cystic fibrosis bronchiectasis. Respiration 2015;89:181-189. 4. Marra AM, Egenlauf B, Bossone E, Eichstaedt C, Grünig E, Ehlken N: Principles of rehabilitation and reactivation: pulmonary hypertension. Respiration 2015;89:265-273.

\section{KARGER 125}

C 2015 S. Karger AG, Basel

$0025-7931 / 15 / 0895-0353 \$ 39.50 / 0$
Daniel Langer

Laboratory of Respiratory Diseases

KU Leuven - Campus Gasthuisberg - O\&N1

Herestraat 49 box 706, BE-3000 Leuven (Belgium)

E-Mail daniel.langer@ faber.kuleuven.be 
based exercise or pedometer-based walking interventions might be interesting alternatives to supervised outpatient rehabilitation interventions in the long-term posttransplant phase and warrant further investigation.

() 2015 S. Karger AG, Basel

\section{Introduction}

Lung transplantation is an established treatment for patients with end-stage lung disease [1]. During the last two decades, considerable advances in organ preservation, surgical techniques, immunosuppression and antibiotic therapy have contributed to an improvement in postoperative survival. Adults who underwent primary lung transplantation in the era January 1990 through June $2012(n=41,767)$ had a median survival of 5.7 years [2]. Centers performing more than 20 surgical procedures annually achieve significantly better outcomes than centers performing less transplantations [3]. With increasing survival rates after lung transplantation, more attention has been directed towards the importance of improving exercise capacity, independent functioning, and quality of life (QOL) in these patients [4-6].

It has been observed that despite near-normal lung function, exercise intolerance and reductions in QOL often persist up to years after transplantation $[4,5,7-14]$. In spite of substantial improvements in the general QOL in comparison with pretransplant values, patients keep reporting limitations in daily physical functioning after transplantation $[4,5]$. Despite an almost complete restoration of lung function after surgery, these persistent impairments underscore the relevance of extrapulmonary factors in patients undergoing lung transplantation [15]. Several aspects that might be addressed by rehabilitation interventions are known to contribute to these persisting impairments. Physiological changes associated with severe and chronic lung disease, limb muscle dysfunction, inactivity/deconditioning, and nutritional depletion can affect exercise capacity and physical functioning in candidates for lung transplantation [16]. After transplantation, extended hospital and intensive care unit (ICU) stay, prolonged sedentary time and persisting inactivity, immunosuppressant medications and episodes of organ rejection may all impact lung recipients' recovery in terms of exercise tolerance and QOL [16].

An important contributor to the persisting reductions in exercise capacity is peripheral muscle dysfunction [8, $11,17-20]$. Reduced muscle mass and reductions in quadriceps strength are consistently observed in the pretrans- plant period, and these reductions have been shown to persist up to 3 years into the posttransplant period [21]. Many lung-transplant recipients report leg fatigue as the main symptom limiting exercise, as opposed to shortness of breath (dyspnea), which is reported as the main limiting symptom by most patients before undergoing surgery [22]. Structural and functional alterations similar to those found in patients with chronic obstructive pulmonary disease, including reductions in type I fibers and altered oxidative enzymes favoring anaerobic metabolism, have been identified in lung recipients with various lung diseases $[13,22,23]$.

The long-term use of corticosteroids, which has been associated with limb muscle atrophy and myopathy [24, 25], as well as immunosuppression with calcineurin inhibitors, which has been shown to negatively impact mitochondrial respiration and muscle remodelling [26, 27], may further contribute to the limb muscle dysfunction and impairments in exercise capacity after transplantation [16].

Based on objective accelerometry-based activity monitor measurements, it has been shown that candidates for lung transplantation are markedly inactive in daily life $[28,29]$. After a further increase in sedentary behavior during hospitalization and inactivity comparable to pretransplant values immediately after hospital discharge, participation in daily activities increases beyond 3 and 6 months after transplantation $[30,31]$ but remain reduced in comparison with healthy age-matched controls up to 1 year after transplantation (fig. 1) [30, 32]. Daily step count, standing time and moderate-intense activity of lung recipients 1 year after transplantation were shown to be reduced by 42,29 and $66 \%$, respectively, relative to controls [32]. These reductions in participation in daily physical activity were associated with impairments in physical fitness and health-related QOL [32].

Increased participation in daily physical activity after transplantation might be beneficial to improve exercise capacity and reduce the risk of developing highly prevalent morbidities after solid organ transplantation, such as osteoporosis, muscle dysfunction, and metabolic/cardiovascular abnormalities [2]. Increased participation in physical activity and associated health effects could either be achieved by supervised exercise training interventions in the early posttransplant period or by lifestyle physical activity programs, such as pedometer-based walking interventions, in the later posttransplant period. Weight gain after transplantation is a common problem, and metabolic/cardiovascular morbidities such as hypertension, diabetes, and hyperlipidemia, which might be mod- 
Fig. 1. Patients' participation in daily physical activity before (pre-LTX) and 1 year after (1y-post-LTX) lung transplantation in comparison with healthy age-matched control subjects (healthy). Daily step count is illustrated in the left panel and time spent in activities requiring $>2$ metabolic equivalents (METs) is summarized in the right panel. Percentages given above the preLTX and 1y-post-LTX columns refer to the averages in these groups expressed relative to healthy controls. Graphs were constructed with data from $[28,32]$.

Fig. 2. Maximal isometric quadriceps strength (QF, left panel) and 6-min walking distance (6MWD, right panel) expressed as percentage of normative reference values specific to the demographic characteristics of participants (\%pred) in a cohort of patients that was longitudinally assessed before lung transplantation (pre), immediately after hospital discharge (post), as well as 3 months (3m-post), and 12 months (1ypost) after lung transplantation. One part of this cohort was randomly allocated to receive a supervised exercise training program during the first 3 months following hospital discharge (training); the other group (control) received usual care. Graphs were constructed with data from [30].
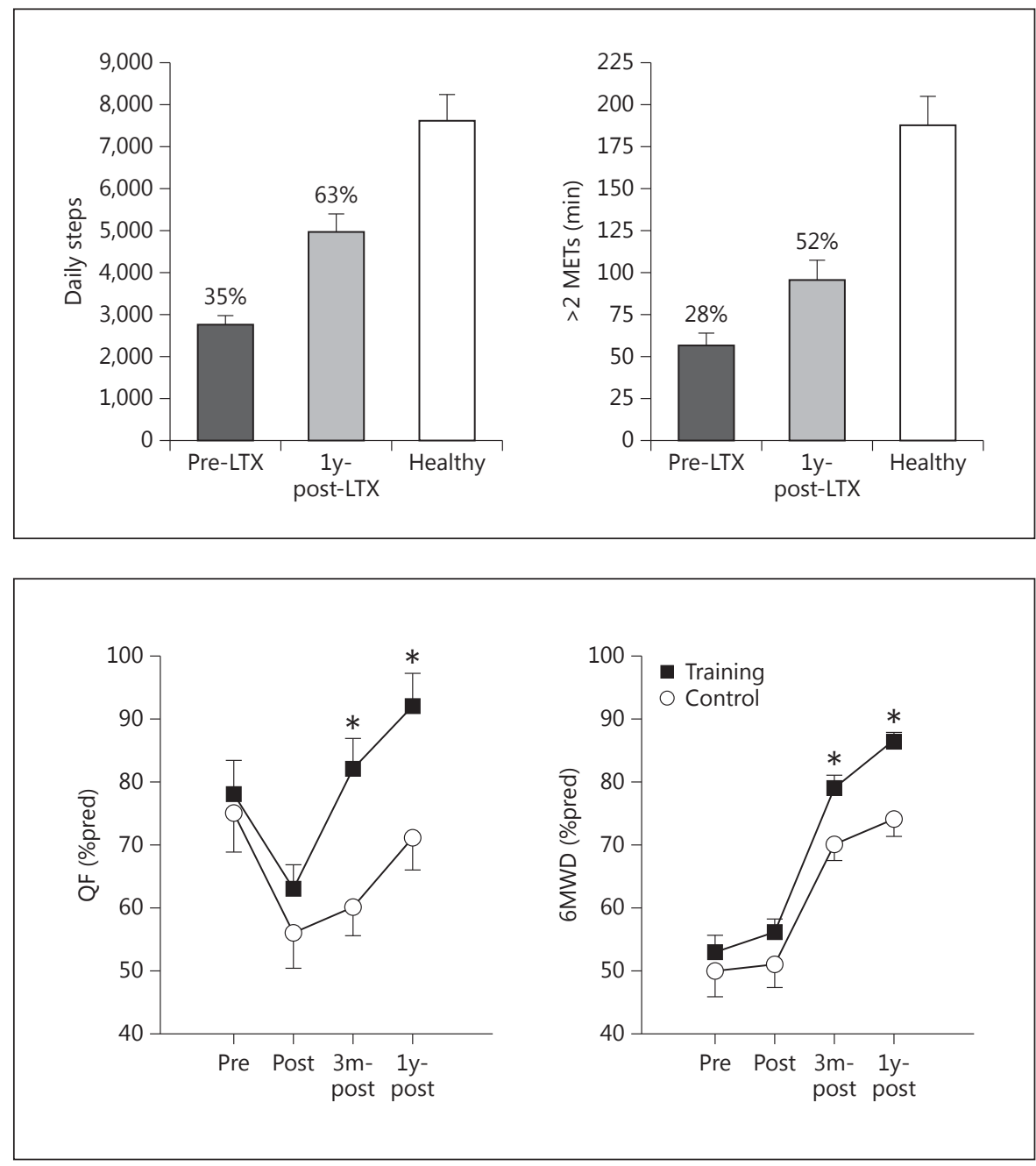

ifiable by physical activity and exercise, rank among the five most common morbidities after lung transplantation $[2,33]$.

Given these persisting impairments and limitations, rehabilitation programs including exercise training should definitely have a role in improving exercise tolerance, physical activity levels, peripheral muscle function, and physical functioning in these patients. In the following paragraphs, the available evidence for rehabilitation interventions before transplantation, during hospitalization after transplantation, and in the early $(\leq 12$ months after hospital discharge) and late ( $>12$ months after hospital discharge) posttransplant phase, will be reviewed. Both evidence-and experience-based content for rehabilitation interventions will be proposed and recommendations for further research will be made.

Rehabilitation in Lung Transplantation

\section{Rehabilitation before Transplantation}

Rehabilitation plays an important role in the preoperative management of patients [15]. Pretransplant pulmonary rehabilitation can help individuals to maintain or optimize their functional status before surgery [34]. This seems valuable given the observed further reductions in peripheral muscle strength and the slow spontaneous recoveries of exercise capacity and physical activity that are observed in the immediate postoperative phase after hospital discharge ( $\leq 12$ months after transplantation), despite immediate reductions in breathlessness and patients no longer being limited by ventilatory impairments (fig. 2, 3) [21, 28, 30].

Rehabilitation can further provide patients with a comprehensive knowledge base regarding the upcoming surgery, potential complications, and the impact of post- 
Fig. 3. Daily time spent walking (left panel) and with activities requiring at least 3 metabolic equivalents (METs, right panel) expressed as percentage of normative reference values specific to the demographic characteristics of participants (\%pred) in a cohort of patients that was longitudinally assessed before lung transplantation (pre), immediately after hospital discharge (post), as well as 3 months (3m-post), and 12 months (1y-post) after lung transplantation. One part of this cohort was randomly allocated to receive a supervised exercise training program during the first 3 months after hospital discharge (training); the other group (control) received usual care. Dashed lines represent average values observed in healthy age-matched control subjects. Graphs were constructed with data from $[28,30,32]$.

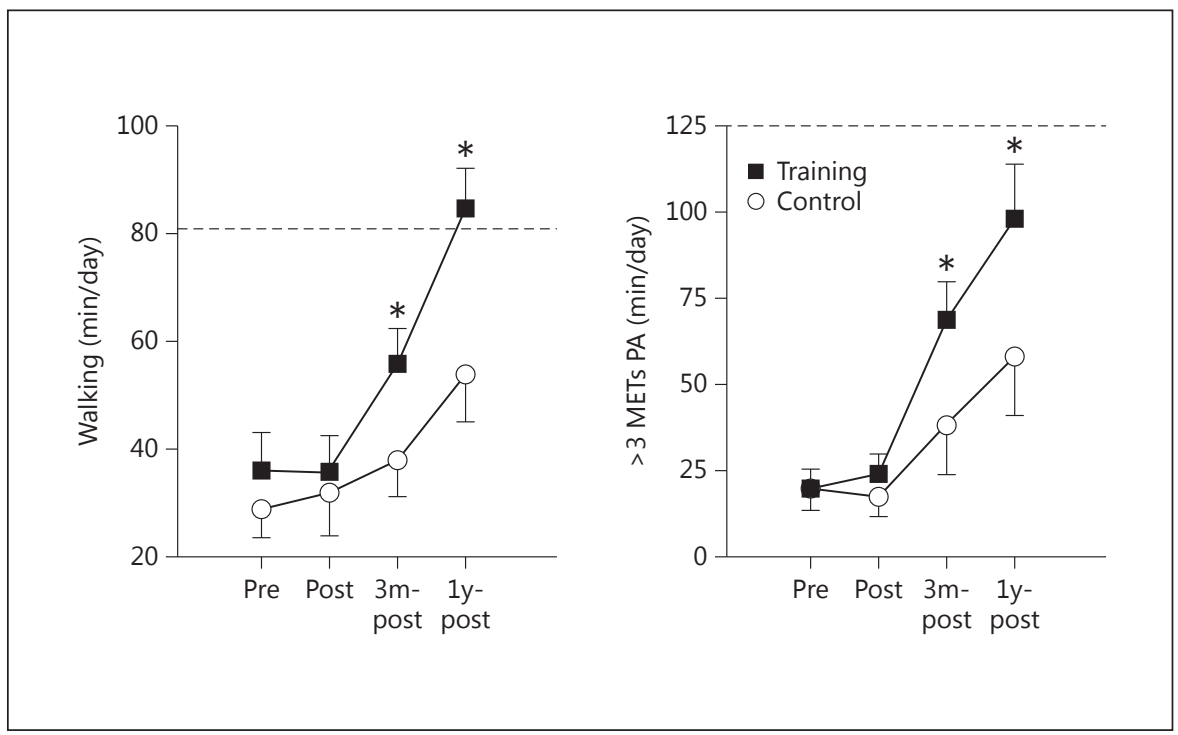

Table 1. Suggested educational content of rehabilitation before lung transplantation

Educational topics before transplantation

Familiarization with the surgical procedure

Preparation for the perioperative period

- Secretion management

- Controlled coughing techniques

- Incentive spirometry

- Chest tubes

- Wound and pain management

- Importance of early mobilization

Disease-specific educational topics

- Anatomic and physiologic basis of symptoms

- Importance and proper use of supplemental oxygen therapy

- Management of daily activities: pacing, energy conservation, and when to stop exercise

Table content adapted from Rochester et al. [34].

operative medications [34]. Since impaired exercise capacity is a predictor of thoracic surgery outcomes and survival, rehabilitation might have the potential to improve surgical outcomes [15]. These potential benefits of pretransplant rehabilitation are also acknowledged in the latest joint American Thoracic Society/European Respiratory Society official statement on pulmonary rehabilitation [35]. In spite of the high disease severity in candidates for lung transplantation, pretransplant rehabilitation has consistently been shown to be feasible and capable of improving functional exercise capacity and
QOL if offered appropriately [36-38]. In a cohort of 345 candidates for lung transplantation, Li et al. [39] found that every 100 -meter increase in 6-min walking distance was associated with a 2.6-day decrease in the median length of hospital stay. No formal guidelines exist regarding the optimal methods for exercise training and educational components of pulmonary rehabilitation programs for patients preparing for lung transplantation. In the absence of comparative studies and sufficient evidence, it might therefore be advisable to follow general recommendations for outpatient pulmonary rehabilitation programs. These should include multimodality aerobic and strength exercise training of the lower and upper limbs on 2-3 days/week for at least 6-8 weeks at the highest tolerable intensity guided by symptoms [15]. Inspiratory muscle training might also be useful in selected patients with pronounced inspiratory muscle weakness. Patients should be closely monitored and the underlying disease for which the patient is undergoing transplantation should be taken into account [34]. In general, individuals have severe exercise limitation and gas exchange disturbances and often experience severe symptoms of dyspnea during activities [35]. Exercise modalities that reduce ventilatory needs in comparison with whole-body endurance training, such as interval training $[36,40]$, resistance training [41], or 1-legged exercise [42], might be useful to ensure optimal stimulation of the limb muscles during training sessions [43]. In the absence of formal guidelines, the suggested content of exercise training and education before transplantation has recently been proposed by Rochester et al. [34] and is presented in tables 1 and 2. 
Table 2. Suggested elements of exercise training during rehabilitation before lung transplantation

- Begin with initial evaluation that examines hemodynamic stability, oxygen requirements, bone health, body mass index, medical comorbidities, respiratory mechanics, and overall functional capacity.

- Complete patient assessment using psychological, healthrelated and generic (e.g. SF-36) QOL measures, shortnessof-breath questionnaires, manual muscle testing, and 6-min walking distance test.

- $\quad$ PR should consist of exercise training, including progressive aerobic exercise and upper/lower extremity strengthening under close supervision and continuous monitoring.

- Exercise should begin at low intensity and be progressed gradually to the highest capacity tolerated by the individual, maintaining adequate oxygenation during activity.

- Place strong emphasis on patient/caregiver education, as well as psychological, dietary and occupational therapy support.

- Frequent reassessments are necessary because of the progression of the underlying lung disease; close communication with patients' health care providers outside PR is essential.

Table content adapted from Rochester et al. [34]. PR = Pulmonary rehabilitation.
Table 3. Suggested elements of rehabilitation during hospitalization after lung transplantation

- Begin approximately $24 \mathrm{~h}$ postoperatively, with an emphasis on early mobilization (e.g. bed cycle, neuromuscular electrical stimulation), breathing exercises, secretion clearance, and posture improvement.

- Early in-patient postoperative rehabilitation should include breathing retraining, reassessing supplemental oxygen requirements, balancing activities, building upper and lower extremity range of motion, and managing any neuropathic pain.

- Because of incisional pain and the denervated cough reflex of the donor lung, patients require direction and encouragement to cough.

- At a later stage, begin with transfers from bed to chair and start ambulation using a specialized walker, with careful management of chest tubes and pain.

- Exercise progression should gradually incorporate lower limb resistance training.

- Lifting and upper limb range of motion precautions and limitations persist up to 6 weeks postoperatively dependent on the type of surgical approach.

- Ensure that lower extremity strength, balance, and gait are sufficient to ensure patient safety and minimize the risk of falls before hospital discharge.

- Necessary medical and adaptive equipment should be provided at discharge.

Table content adapted from Rochester et al. [34].
Larger studies will be needed to determine the efficacy of different exercise regimens on functional capacity and posttransplant recovery. The role of resistance training (possibly combined with nutritional interventions) to improve muscle strength and muscle mass, particularly in frail patients in the pretransplant phase, and the impact of this intervention on posttransplant recovery, has not been explored so far. These aspects have recently been identified as important future areas of study by an international expert panel [16].

\section{Hospitalization following Transplantation}

Not much research has been performed concerning the rehabilitation of patients during hospitalization in the early preoperative period. Most of the suggested elements of rehabilitation during hospitalization formulated in this paragraph are therefore consensus or experience based. The importance of early (starting $24 \mathrm{~h}$ postoperatively) mobilization in the ICU is being increasingly recognized $[44,45]$. Even though they have not been formally stud- ied, treatment principles of early mobilization are probably very useful in the lung-transplant population with their known pre- and posttransplant limb muscle dysfunction. ICU-acquired weakness is a highly prevalent problem that is related to the duration of mechanical ventilation, use of sedative agents, neuromuscular blockers, corticosteroids, and reduced physical activity resulting from immobilization in patients admitted to the ICU [46, 47]. Reductions in muscle mass and muscle strength occur early after admission to the ICU and are associated with long-term functional disability [48], and increased mortality [47]. Early active muscle training would be an ideal treatment to attenuate this ICU-acquired weakness. Active lower limb resistance training has previously been shown to be an effective and feasible treatment option in severely disabled patients [41]. In the early postoperative phase, however, a large proportion of patients are unable to participate in any active mobilization. Neuromuscular electrical stimulation might be an alternative treatment strategy to prevent deterioration of muscle function in the very early postsurgical phase [49]. When patients leave the ICU, a progressively more active treatment ap- 
proach should be adopted focusing mainly on building sufficient lower extremity strength, balance, and gait to ensure patient safety and minimize the risk of falls prior to hospital discharge. The suggested content of rehabilitation during hospitalization after transplantation is summarized in table 3.

\section{Immediate Posttransplant Phase (Hospital Discharge after $\leq 12$ Months)}

Despite the well-documented persisting physical impairments, increased risks for cardiovascular disease and the general belief that exercise training has potential for both short- and long-term benefits in this population, there is a lack of randomized controlled trials (RCTs) on exercise training for transplant recipients $[16,50]$. In a recent systematic review examining the health benefits and risks associated with exercise following solid organ transplantation, only 15 RCTs were identified across kidney $(\mathrm{n}=2)$, liver $(\mathrm{n}=1)$, heart $(\mathrm{n}=9)$, and lung $(\mathrm{n}=3)$ transplant populations [51].

Of three RCTs conducted after lung transplantation, two were performed in the immediate posttransplant phase [30, 52]. Langer et al. [30] investigated the effects of a supervised exercise training intervention following general recommendations for outpatient pulmonary rehabilitation programs. The intervention involved 12 weeks of high-intensity, symptom-guided, lower limb endurance and resistance training starting immediately after hospital discharge $(\mathrm{n}=18)$. Three weekly sessions of this intervention were compared with a standard medical care control group receiving instructions on increasing their daily physical activity $(\mathrm{n}=16)$. Mitchell et al. [52] focused on osteoporosis as a highly prevalent morbidity and studied the effects of a supervised 6-month lumbar extension exercise training program $(n=8)$, initiated 8 weeks after hospital discharge, on bone mineral density of the lumbar vertebrae in comparison with a usual care group $(n=8)$. In both studies, significant between-group differences after the intervention were found. While the benefits in the study by Mitchell et al. [52] were confined to improvements in bone mineral density, Langer et al. [30] could demonstrate betweengroup differences in several outcomes. The peak work rate during a maximal incremental cardiopulmonary cycle exercise test, 6-min walking distance (fig. 2), quadriceps strength (fig. 2), participation in daily physical activity (fig. 3), as well as physical functioning and role limitation domains of QOL were significantly higher in patients who participated in the exercise program up to 1 year after transplantation [30].

Three further cohort studies investigated the effects of 8-12 weeks of endurance training $(n=8)$ [53] and combined endurance and resistance training ( $\mathrm{n}=36$ in both studies) $[54,55]$ immediately after hospital discharge. In these studies, significant improvements were found in peak oxygen consumption [53], 6-min walking distance $[54,55]$, limb muscle strength $[54,55]$, and QOL [55]. However, findings from cohort studies obtained in this phase after transplantation need to be interpreted with caution. In the absence of a control group, it is not possible to differentiate the effects of the intervention from the considerable improvements that occur spontaneously during this period (fig. 2, 3).

In summary, there are indications from several small single-center studies that outpatient rehabilitation involving supervised exercise training might be beneficial for patients to improve clinically relevant outcomes in the immediate posttransplant phase. However, the availability of high-quality RCTs is limited. None of the existing RCTs measured the effects of exercise training on crucial long-term outcomes such as sustained improvements in QOL and participation in daily activity, survival, incidence of morbidities, and cost-effectiveness [16]. Sufficiently powered, high-quality, multicenter RCTs are needed to address these important issues. Cohort studies in this patient group offer limited information because of the considerable natural recovery that is observed in the immediate posttransplant phase. The suggested content of rehabilitation in the immediate posttransplant phase is summarized in table 4 .

\section{Long-Term Posttransplant Phase (Hospital Discharge after $>12$ Months)}

One RCT compared the effects of a 4-week inpatient pulmonary rehabilitation program $(\mathrm{n}=30)$ in comparison with an outpatient physiotherapy group $(\mathrm{n}=30)$ in long-term survivors of lung transplantation (average posttransplant time of participants $=234$ weeks) [56]. No significant between-group differences in exercise capacity or QOL were reported. Both groups achieved significant within-group improvements (both $\mathrm{p}<0.001$ ) in 6-min walking distance (intervention group: $45 \mathrm{~m}$; control group: $24 \mathrm{~m}$ ). Whether the absence of between-group differences was due to the short intervention period (4 weeks) or the 'active' control intervention is unclear. While the intervention group consisted of combined en- 
Table 4. Suggested elements of rehabilitation in the immediate posttransplant phase

- Outpatient PR may resume immediately after hospital discharge. Functional capacity (e.g. 6-min walking distance or cardiopulmonary exercise testing) and strength measurements should be performed to establish a postoperative baseline.

- Closely monitor hygiene measures to prevent infections and reduce the risk for acute rejection. Patients should be encouraged to wear face masks during group outpatient PR sessions and to disinfect their hands as well as handles of exercise training equipment before and after each exercise.

- Progress the exercise training to higher intensity and duration over time (patients are no longer limited by ventilatory impairments).

- Monitor comorbidities such as diabetes and osteoporosis; activities that include excessive flexion and rotation should be avoided to reduce the risk of possible vertebral compression fracture. Blood glucose must be carefully monitored because adjustments may occur frequently as a result of the influx of multiple postoperative medications and corticosteroids.

- Lung recipients are prone to developing tendinopathies [62, 63]. Monitor symptoms closely and avoid overburdening tendons by repetitive tasks against high resistances. Make use of interval exercises, sufficient warm-up and stretching procedures to avoid injuries.

Table content adapted from Rochester et al. [34]. PR = Pulmonary rehabilitation.

durance and resistance exercises for the upper and lower limbs, the control group also involved a 'cardiovascular exercise' component. However, the training intensity of exercises was unfortunately not specified for either of the two groups.

Three cohort studies demonstrated positive effects of exercise training on muscle function and exercise capacity in the long-term posttransplant phase [57-59]. Stiebellehner et al. [59] studied the effects of 6 weeks of aerobic endurance exercise on a cycle ergometer in a group of 9 patients (average posttransplant time $=52$ weeks). $\mathrm{Pa}$ tients trained on 3-5 days/week starting at $60 \mathrm{~min}$ and building up to $120 \mathrm{~min} /$ week at $60 \%$ of their maximum heart rate reserve. Patients achieved statistically significant improvements in maximal exercise capacity and minute ventilation at iso-work rate. Another interesting feature of the study was the fact that patients were followed for 6 weeks during their daily activities before starting the exercise training intervention. In contrast to patients in the immediate posttransplant phase, no sponta-

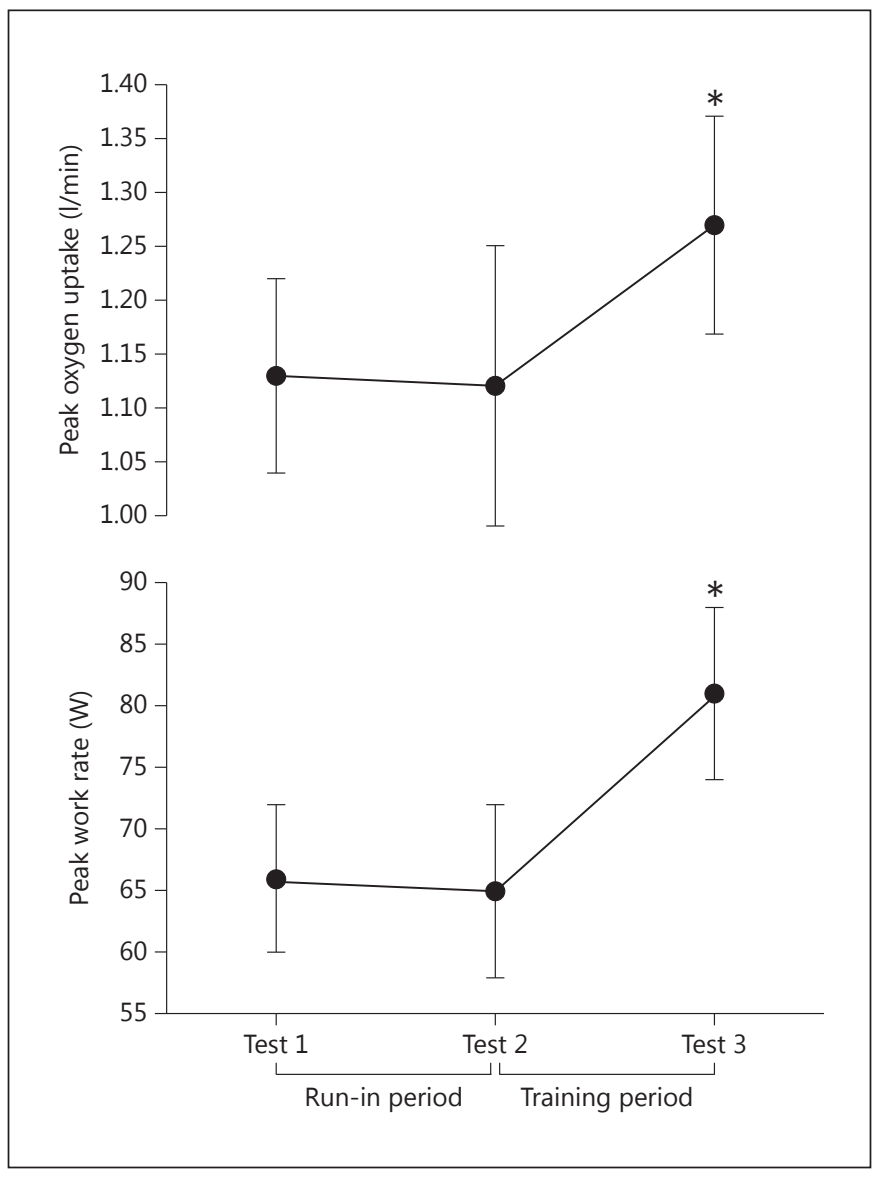

Fig. 4. Peak oxygen uptake (top panel) and peak work rate (bottom panel) over a study period of 12 weeks ( 6 weeks run-in and 6 weeks aerobic endurance training). Values are presented as means \pm SEM. The asterisk indicates $\mathrm{p}<0.05$ in comparison with baseline. The graph was adapted from Stiebellehner et al. [59].

neous improvements were observed during this run-in period, lending more credibility to cohort studies in this population (fig. 4 ).

Two other studies demonstrated positive effects of a home-based cycle endurance training program in a group of 12 lung recipients (average posttransplant time $=156$ weeks). Patients trained 3 times a week for $30 \mathrm{~min}$ starting at $50 \%$ and building up to $80 \%$ of their peak work rate for a duration of 3 months. They were monitored by phone calls, and training sessions were remotely supervised with heart rate monitors. In addition to significant improvements in endurance time and QOL, the authors also observed specific structural and functional changes in the limb muscles of these subjects after training. These included improvements in mitochondrial function [57], in- 
creased muscle strength [58], an increase in oxidative type I muscle fibers [58], and increases in the diameter of type II muscle fibers [58]. Structural adaptations observed in the limb muscles were comparable to those observed in healthy control subjects after a similar training intervention [57].

Chronic rejection is a widespread problem that frequently occurs in the long-term posttransplant phase in these patients [60]. It is diagnosed based on a worsening of expiratory flow limitation and results in increased symptoms of dyspnea, reductions in functional exercise capacity and QOL $[60,61]$. Referring these patients to a supervised outpatient rehabilitation program might be a viable treatment option to improve symptoms and daily functioning. This has, however, not been formally studied so far.

In summary, these data obtained from small singlecenter studies indicate that (given a sufficient training duration and intensity) improvements in exercise capacity and limb muscle function seem achievable in the longterm posttransplant phase. Home-based training with remote monitoring may be a useful alternative to fully supervised outpatient rehabilitation programs in these patients [58]. This might be especially useful given the large distances that many patients have to cover to attend supervised outpatient programs. Emerging telehealth interventions based on novel communication technologies might therefore be an especially interesting alternative for this target population. The effects of pedometer-based walking programs have not been tested so far in this population and might be another interesting alternative to supervised exercise interventions.

\section{Conclusions and Research Needs}

From the limited number of single-center studies performed in small samples it can be concluded that outpatient rehabilitation programs including supervised exercise training can be effective in improving limb muscle dysfunction, exercise capacity, and QOL both before and after transplantation. Appropriate training parameters in terms of duration, frequency, and intensity seem necessary to achieve improvements in limb muscle function and exercise capacity. In the absence of comparative studies and sufficient evidence, it is advisable to follow general recommendations for exercise training interventions during outpatient pulmonary rehabilitation programs. The short and long-term effects of exercise and/or physical activity interventions on the risk of organ rejection, survival, incidence of infections, development of obesity, hypertension, diabetes and/or metabolic syndrome, as well as on QOL should be further explored. Remotely monitored (telehealth) home-based exercise programs or pedometer-based walking interventions might be interesting alternatives to supervised outpatient rehabilitation interventions in the long-term posttransplant phase and should be further investigated.

\section{References}

1 Arcasoy SM, Kotloff RM: Lung transplantation. N Engl J Med 1999;340:1081-1091.

- 2 Yusen RD, Edwards LB, Kucheryavaya AY, Benden C, Dipchand AI, Dobbels F, Goldfarb SB, Levvey BJ, Lund LH, Meiser B, Stehlik J: The registry of the International Society for Heart and Lung Transplantation: thirty-first adult lung and heart-lung transplant report 2014; focus theme: retransplantation. J Heart Lung Transplant 2014;33:1009-1024.

-3 Weiss ES, Allen JG, Meguid RA, Patel ND, Merlo CA, Orens JB, Baumgartner WA, Conte JV, Shah AS: The impact of center volume on survival in lung transplantation: an analysis of more than 10,000 cases. Ann Thorac Surg 2009;88:1062-1070.

4 Myaskovsky L, Dew MA, McNulty ML, Switzer GE, DiMartini AF, Kormos RL, McCurry KR: Trajectories of change in quality of life in 12-month survivors of lung or heart transplant. Am J Transplant 2006;6:1939-1947.
5 Smeritschnig B, Jaksch P, Kocher A, Seebacher G, Aigner C, Mazhar S, Klepetko W: Quality of life after lung transplantation: a crosssectional study. J Heart Lung Transplant 2005;24:474-480.

-6 Gerbase MW, Soccal PM, Spiliopoulos A, Nicod LP, Rochat T: Long-term health-related quality of life and walking capacity of lung recipients with and without bronchiolitis obliterans syndrome. J Heart Lung Transplant 2008;27:898-904.

7 Lands LC, Smountas AA, Mesiano G, Brosseau L, Shennib H, Charbonneau M, Gauthier R: Maximal exercise capacity and peripheral skeletal muscle function following lung transplantation. J Heart Lung Transplant 1999;18: 113-120.

8 Schwaiblmair M, Reichenspurner H, Muller C, Briegel J, Furst H, Groh J, Reichart B, Vogelmeier C: Cardiopulmonary exercise testing before and after lung and heart-lung trans- plantation. Am J Respir Crit Care Med 1999; 159:1277-1283.

-9 Ambrosino N, Bruschi C, Callegari G, Baiocchi S, Felicetti G, Fracchia C, Rampulla C: Time course of exercise capacity, skeletal and respiratory muscle performance after heartlung transplantation. Eur Respir J 1996;9: 1508-1514.

10 Krieger AC, Szidon P, Kesten S: Skeletal muscle dysfunction in lung transplantation. J Heart Lung Transplant 2000;19:392-400.

11 Pantoja JG, Andrade FH, Stokic DS, Frost AE, Eschenbacher WL, Reid MB: Respiratory and limb muscle function in lung allograft recipients. Am J Respir Crit Care Med 1999;160: 1205-1211.

12 Studer SM, Levy RD, McNeil K, Orens JB: Lung transplant outcomes: a review of survival, graft function, physiology, health-related quality of life and cost-effectiveness. Eur Respir J 2004;24:674-685. 
-13 Wang XN, Williams TJ, McKenna MJ, Li JL, Fraser SF, Side EA, Snell GI, Walters EH, Carey MF: Skeletal muscle oxidative capacity, fiber type, and metabolites after lung transplantation. Am J Respir Crit Care Med 1999; 160:57-63.

-14 Bartels MN, Armstrong HF, Gerardo RE, Layton AM, Emmert-Aronson BO, Sonett JR, Arcasoy SM: Evaluation of pulmonary function and exercise performance by cardiopulmonary exercise testing before and after lung transplantation. Chest 2011;140:1604-1611.

15 Rochester CL: Pulmonary rehabilitation for patients who undergo lung-volume-reduction surgery or lung transplantation. Respir Care 2008;53:1196-1202.

-16 Mathur S, Janaudis-Ferreira T, Wickerson L, Singer LG, Patcai J, Rozenberg D, Blydt-Hansen T, Hartmann EL, Haykowsky M, Helm D, High K, Howes N, Kamath BM, Lands L, Marzolini S, Sonnenday C: Meeting report: consensus recommendations for a research agenda in exercise in solid organ transplantation. Am J Transplant 2014;14:2235-2245.

-17 Reinsma GD, ten Hacken NHT, Grevink RG, Van der Bij W, Koer GH, van Weert E: Limiting factors of exercise performance 1 year after lung transplantation. J Heart Lung Transplant 2006;25:1310-1316.

18 Mathur S, Reid WD, Levy RD: Exercise limitation in recipients of lung transplants. Physical Therapy 2004;84:1178-1187.

19 van Adrichem EJ, Reinsma GD, van den Berg S, Van der Bij W, Erasmus ME, Krijnen WP, Dijkstra PU, van der Schans CP: Predicting 6-Minute Walking Distance in Lung Transplant Recipients: A Longitudinal Study of 108 Patients. Phys Ther 2014, Epub ahead of print.

20 Williams TJ, McKenna MJ: Exercise limitation following transplantation. Compr Physiol 2012;2:1937-1979.

-21 Rozenberg D, Wickerson L, Singer LG, Mathur S: Sarcopenia in lung transplantation: a systematic review. J Heart Lung Transplant 2014;33:1203-1212.

-22 Williams TJ, Patterson GA, McClean PA, Zamel N, Maurer JR: Maximal exercise testing in single and double lung transplant recipients. Am Rev Respir Dis 1992;145:101-105.

23 Evans AB, AlHimyary AJ, Hrovat MI, Pappagianopoulos P, Wain JC, Ginns LC, Systrom DM: Abnormal skeletal muscle oxidative capacity after lung transplantation by P31-MRS. Am J Respir Crit Care Med 1997; 155:615-621.

-24 Schakman O, Kalista S, Barbe C, Loumaye A, Thissen JP: Glucocorticoid-induced skeletal muscle atrophy. Int J Biochem Cell Biol 2013; 45:2163-2172.

25 Schakman O, Gilson H, Thissen JP: Mechanisms of glucocorticoid-induced myopathy. J Endocrinol 2008; 197:1-10.

26 Sakuma K, Yamaguchi A: The functional role of calcineurin in hypertrophy, regeneration, and disorders of skeletal muscle. J Biomed Biotechnol 2010;2010:721219.
7 Sanchez H, Zoll J, Bigard X, Veksler V, Mettauer B, Lampert E, Lonsdorfer J, VenturaClapier R: Effect of cyclosporin A and its vehicle on cardiac and skeletal muscle mitochondria: relationship to efficacy of the respiratory chain. Br J Pharmacol 2001;133:781-788.

28 Langer D, Iranzo MA, Burtin C, Verleden SE, Vanaudenaerde BM, Troosters T, Decramer M, Verleden GM, Gosselink R: Determinants of physical activity in daily life in candidates for lung transplantation. Respir Med 2012; 106:747-754

29 Wickerson L, Mathur S, Helm D, Singer L, Brooks D: Physical activity profile of lung transplant candidates with interstitial lung disease. J Cardiopulm Rehabil Prev 2013;33: 106-112.

30 Langer D, Burtin C, Schepers L, Ivanova A, Verleden G, Decramer M, Troosters T, Gosselink R: Exercise training after lung transplantation improves participation in daily activity: a randomized controlled trial. Am J Transplant 2012;12:1584-1592.

-31 Wickerson L, Mathur S, Singer LG, Brooks D: Physical activity levels early after lung transplantation. Phys Ther 2015;95:517-525.

- 32 Langer D, Gosselink R, Pitta F, Burtin C, Verleden G, Dupont L, Decramer M, Troosters T: Physical activity in daily life 1 year after lung transplantation. J Heart Lung Transplant 2009;28:572-578.

- 33 Forli L, Bollerslev J, Simonsen S, Isaksen GA, Godang K, Pripp AH, Bjortuft O: Disturbed energy metabolism after lung and heart transplantation. Clin Transplant 2011;25:E136E143.

34 Rochester CL, Fairburn C, Crouch RH: Pulmonary rehabilitation for respiratory disorders other than chronic obstructive pulmonary disease. Clin Chest Med 2014;35:369389.

35 Spruit MA, Singh SJ, Garvey C, et al: An official American Thoracic Society/European Respiratory Society statement: key concepts and advances in pulmonary rehabilitation. Am J Respir Crit Care Med 2013;188:e13-e64.

36 Gloeckl R, Halle M, Kenn K: Interval versus continuous training in lung transplant candidates: a randomized trial. J Heart Lung Transplant 2012;31:934-941.

- 37 Jastrzebski D, Ochman M, Ziora D, Labus L, Kowalski K, Wyrwol J, Lutogniewska W, Maksymiak M, Ksiazek B, Magner A, Bartoszewicz A, Kubicki P, Hydzik G, Zebrowska A, Kozielski J: Pulmonary rehabilitation in patients referred for lung transplantation. Adv Exp Med Biol 2013;755:19-25.

38 Florian J, Rubin A, Mattiello R, Fontoura FF, Camargo JJ, Teixeira PJ: Impact of pulmonary rehabilitation on quality of life and functional capacity in patients on waiting lists for lung transplantation. J Bras Pneumol 2013;39: 349-356.

39 Li M, Mathur S, Chowdhury NA, Helm D, Singer LG: Pulmonary rehabilitation in lung transplant candidates. J Heart Lung Transplant 2013;32:626-632.
40 Vogiatzis I, Nanas S, Roussos C: Interval training as an alternative modality to continuous exercise in patients with COPD. Eur Respir J 2002;20:12-19.

41 Troosters T, Probst VS, Crul T, Pitta F, Gayan-Ramirez G, Decramer M, Gosselink R: Resistance training prevents deterioration in quadriceps muscle function during acute exacerbations of chronic obstructive pulmonary disease. Am J Respir Crit Care Med 2010;181: 1072-1077.

42 Dolmage TE, Goldstein RS: Effects of onelegged exercise training of patients with COPD. Chest 2008;133:370-376.

43 Probst VS, Troosters T, Pitta F, Decramer M, Gosselink R: Cardiopulmonary stress during exercise training in patients with COPD. Eur Respir J 2006;27:1110-1118.

44 Burtin C, Clerckx B, Robbeets C, Ferdinande P, Langer D, Troosters T, Hermans G, Decramer M, Gosselink R: Early exercise in critically ill patients enhances short-term functional recovery. Crit Care Med 2009;37:24992505.

45 Needham DM, Chandolu S, Zanni J: Interruption of sedation for early rehabilitation improves outcomes in ventilated, critically ill adults. Aust J Physiother 2009;55:210.

46 Truong AD, Fan E, Brower RG, Needham DM: Bench-to-bedside review: mobilizing patients in the intensive care unit - from pathophysiology to clinical trials. Crit Care 2009; $13: 216$

47 De Jonghe B, Sharshar T, Lefaucheur JP, Authier FJ, Durand-Zaleski I, Boussarsar M, Cerf C, Renaud E, Mesrati F, Carlet J, Raphael JC, Outin H, Bastuji-Garin S: Paresis acquired in the intensive care unit: a prospective multicenter study. JAMA 2002;288:2859-2867.

48 Herridge MS, Tansey CM, Matte A, Tomlinson G, Diaz-Granados N, Cooper A, Guest CB, Mazer CD, Mehta S, Stewart TE, Kudlow P, Cook D, Slutsky AS, Cheung AM: Functional disability 5 years after acute respiratory distress syndrome. N Engl J Med 2011;364: 1293-1304.

49 Segers J, Hermans G, Bruyninckx F, Meyfroidt G, Langer D, Gosselink R: Feasibility of neuromuscular electrical stimulation in critically ill patients. J Crit Care 2014;29:1082-1088.

50 Wickerson L, Mathur S, Brooks D: Exercise training after lung transplantation: a systematic review. J Heart Lung Transplant 2010;29: 497-503.

51 Didsbury M, McGee RG, Tong A, Craig JC, Chapman JR, Chadban S, Wong G: Exercise training in solid organ transplant recipients: a systematic review and meta-analysis. Transplantation 2013;95:679-687.

52 Mitchell MJ, Baz MA, Fulton MN, Lisor CF, Braith RW: Resistance training prevents vertebral osteoporosis in lung transplant recipients. Transplantation 2003;76:557-562.

53 Ross DJ, Waters PF, Mohsenifar Z, Belman MJ, Kass RM, Koerner SK: Hemodynamic responses to exercise after lung transplantation. Chest 1993;103:46-53. 
54 Maury G, Langer D, Verleden G, Dupont L, Gosselink R, Decramer M, Troosters T: Skeletal muscle force and functional exercise tolerance before and after lung transplantation: a cohort study. Am J Transplant 2008;8:12751281.

55 Munro PE, Holland AE, Bailey M, Button BM, Snell GI: Pulmonary rehabilitation following lung transplantation. Transplant Proc 2009;41:292-295.

56 Ihle F, Neurohr C, Huppmann P, Zimmermann G, Leuchte H, Baumgartner R, Kenn K, Sczepanski B, Hatz R, Czerner S, Frey L, Ueberfuhr P, Bittmann I, Behr J: Effect of inpatient rehabilitation on quality of life and exercise capacity in long-term lung transplant survivors: a prospective, randomized study. J Heart Lung Transplant 2011;30:912-919.

-57 Guerrero K, Wuyam B, Mezin P, Vivodtzev I, Vendelin M, Borel JC, Hacini R, Chavanon O,
Imbeaud S, Saks V, Pison C: Functional coupling of adenine nucleotide translocase and mitochondrial creatine kinase is enhanced after exercise training in lung transplant skeletal muscle. Am J Physiol Regul Integr Comp Physiol 2005;289:R1144-R1154.

58 Vivodtzev I, Pison C, Guerrero K, Mezin P, Maclet E, Borel JC, Chaffanjon P, Hacini R, Chavanon O, Blin D, Wuyam B: Benefits of home-based endurance training in lung transplant recipients. Respir Physiol Neurobiol 2011;177:189-198.

59 Stiebellehner L, Quittan M, End A, Wieselthaler G, Klepetko W, Haber P, Burghuber OC: Aerobic endurance training program improves exercise performance in lung transplant recipients. Chest 1998;113:906-912.

-60 Verleden GM, Vos R, De Vleeschauwer SI, Willems-Widyastuti A, Verleden SE, Dupont LJ, Van Raemdonck DE, Vanaudenaerde BM:
Obliterative bronchiolitis following lung transplantation: from old to new concepts? Transpl Int 2009;22:771-779.

61 Langer D, Cebria I, Iranzo MA, Verleden G, Gosselink R: Clinical evolution in patients with and without bronchiolitis obliterans syndrome diagnosis after lung transplantation. Am J Respir Crit Care Med 2013;187:A1826.

62 Chhajed PN, Plit ML, Hopkins PM, Malouf MA, Glanville AR: Achilles tendon disease in lung transplant recipients: association with ciprofloxacin. Eur Respir J 2002;19:469-471.

63 Barge-Caballero EM, Crespo-Leiro G, Paniagua-Martin MJ, Muniz J, Naya C, BouzasMosquera A, Pinon-Esteban P, Marzoa-Rivas R, Pazos-Lopez P, Cursack GC, Cuenca-Castillo JJ, Castro-Beiras A: Quinolone-related Achilles tendinopathy in heart transplant patients: incidence and risk factors. J Heart Lung Transplant 2008;27:46-51. 